\title{
Climatology of GPS phase scintillation at northern high latitudes for the period from 2008 to 2013
}

\author{
P. Prikryl ${ }^{1,2}$, P. T. Jayachandran ${ }^{2}$, R. Chadwick ${ }^{2}$, and T. D. Kelly ${ }^{2}$ \\ ${ }^{1}$ Geomagnetic Laboratory, Natural Resources Canada, Ottawa, ON, Canada \\ ${ }^{2}$ Physics Department, University of New Brunswick, Fredericton, NB, Canada \\ Correspondence to: P. Prikryl (paul.prikryl@unb.ca)
}

Received: 7 January 2015 - Revised: 30 March 2015 - Accepted: 20 April 2015 - Published: 13 May 2015

\begin{abstract}
Global positioning system scintillation and total electron content (TEC) data have been collected by ten specialized GPS Ionospheric Scintillation and TEC Monitors (GISTMs) of the Canadian High Arctic Ionospheric Network (CHAIN). The phase scintillation index $\sigma_{\Phi}$ is obtained from the phase of the L1 signal sampled at $50 \mathrm{~Hz}$. Maps of phase scintillation occurrence as a function of the altitude-adjusted corrected geomagnetic (AACGM) latitude and magnetic local time (MLT) are computed for the period from 2008 to 2013. Enhanced phase scintillation is collocated with regions that are known as ionospheric signatures of the coupling between the solar wind and magnetosphere. The phase scintillation mainly occurs on the dayside in the cusp where ionospheric irregularities convect at high speed, in the nightside auroral oval where energetic particle precipitation causes field-aligned irregularities with steep electron density gradients and in the polar cap where electron density patches that are formed from a tongue of ionization. Dependences of scintillation occurrence on season, solar and geomagnetic activity, and the interplanetary magnetic field (IMF) orientation are investigated. The auroral phase scintillation shows semiannual variation with equinoctial maxima known to be associated with auroras, while in the cusp and polar cap the scintillation occurrence is highest in the autumn and winter months and lowest in summer. With rising solar and geomagnetic activity from the solar minimum to solar maximum, yearly maps of mean phase scintillation occurrence show gradual increase and expansion of enhanced scintillation regions both poleward and equatorward from the statistical auroral oval. The dependence of scintillation occurrence on the IMF orientation is dominated by increased scintillation in the cusp, expanded auroral oval and at subauroral latitudes for strongly southward IMF. In the polar cap, the IMF
\end{abstract}

$B_{Y}$ polarity controls dawn-dusk asymmetries in scintillation occurrence collocated with a tongue of ionization for southward IMF and with sun-aligned arcs for northward IMF. In investigating the shape of scintillation-causing irregularities, the distributions of scintillation occurrence as a function of "off-meridian" and "off-shell" angles that are computed for the receiver-satellite ray at the ionospheric pierce point are found to suggest predominantly field-aligned irregularities in the auroral oval and L-shell-aligned irregularities in the cusp.

Keywords. Ionosphere (auroral ionosphere; ionospheric irregularities; polar ionosphere)

\section{Introduction}

Space weather impacts the operation of modern technology that relies on global navigation satellite systems (GNSS) including GPS, GLONASS and Galileo, which have become indispensable in precise positioning and time keeping. Ionospheric irregularities cause rapid fluctuations of radio wave amplitude and phase that can degrade GPS positional accuracy and affect performance of radio communication and navigation systems. Variable ionospheric delays and scintillation cause cycle slips, which can lead to loss of lock and affect the performance of radio communications and navigation systems (Aarons, 1982, 1997; Aarons et al., 2000; Basu et al., 1987, 1995, 1998). In spite of improved understanding of ionospheric irregularities, scintillation is difficult to predict for a given ray path because of the complexity of ionospheric irregularity generation, coupling of the solar wind magnetic and electric fields to the ionosphere and dynamic convection of ionospheric plasma. Statistical (empirical) models of scintillation that have been developed for the 


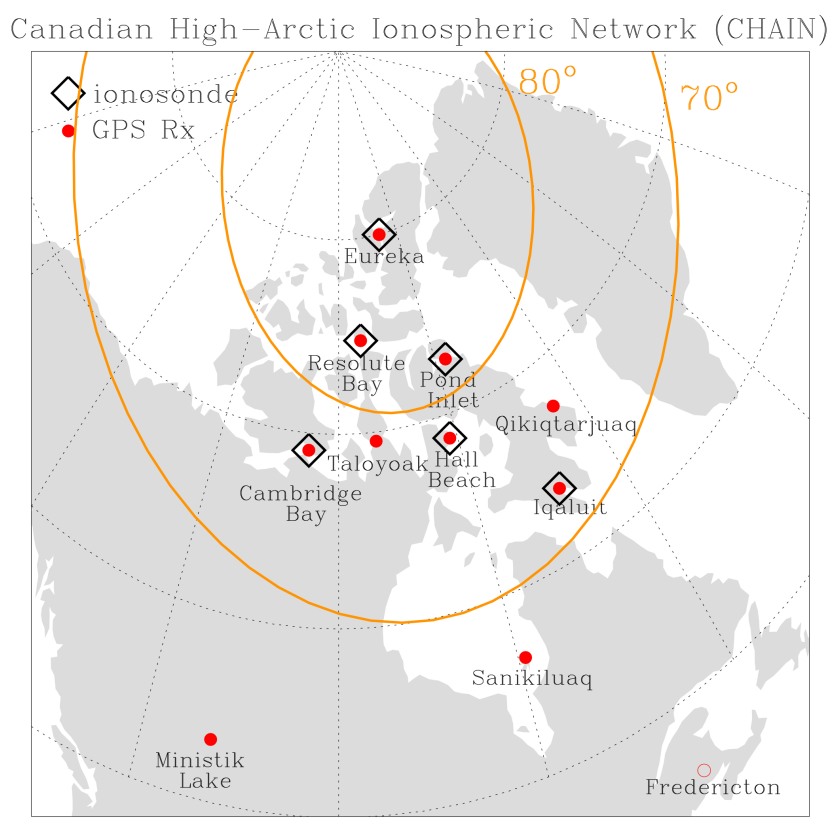

Figure 1. Canadian High Arctic Ionospheric Network (CHAIN): the GPS Ionospheric Scintillation and TEC Monitors and Canadian Advanced Digital Ionosondes (CADIs). The corrected geomagnetic (CGM) latitudes 70 and $80^{\circ}$, in yellow, are superposed over the geographic grid.

equatorial and high-latitude ionospheres (Secan et al., 1995, 1997) used data from past satellite experiments (Wideband, HiLat and Polar BEAR) covering frequencies from VHF to L-band, although the modeling was based on VHF data only. More recently, using satellite in situ measurements of plasma (electron) density fluctuations, the International Reference Ionosphere (IRI) model and the phase screen propagation model, a scintillation climatology model for the high-latitude ionosphere was developed (Wernik et al., 2007).

With a growing number of GNSS Ionospheric Scintillation and TEC Monitors (GISTMs) operating at high latitudes, it has become possible to build a detailed scintillation climatology from accumulated scintillation data in the auroral and polar regions (Spogli et al., 2009; Li et al., 2010; Alfonsi et al., 2011; Prikryl et al., 2011a; Moen et al., 2013). Spogli et al. (2009) and Alfonsi et al. (2011) were the first to describe the essence of what they called the "GroundBased Scintillation Climatology (GBSC)" method, laying down the basis how to obtain maps, in geographic and geomagnetic coordinates, of scintillation occurrence and total electron content (TEC) variations observed by a network of GISTMs, to investigate dependencies on interplanetary magnetic field (IMF) orientation, geomagnetic activity and season and solar cycle. In a comprehensive study of space weather impact on the cusp and polar cap toward understanding plasma instabilities and scintillation in association with cusp flow channels and polar cap patches, Moen et al. (2013) applied the GBSC method to investigate the multi-scale ir- regularity structures resulting from different physical processes that include flow shears and particle precipitation. As these authors pointed out, the phase and amplitude scintillation are biased to different irregularity scale sizes from a few kilometers down to a few hundred meters, which are produced by different processes.

An empirical climatology model of high-latitude GNSS scintillation appears to be the next step to address the questions of forecasting and mitigation of L-band scintillation at high-latitudes (Decker and Pedersen, 2001; Aquino et al., 2007; Strangeways et al., 2011, Moen et al., 2013). One of the ionospheric scintillation models that has been developed is WBMOD (WideBand MODel), based on analysis of large databases of VHF scintillation measurements (Secan et al., 1995, 1997; http://spawx.nwra.com/ionoscint/ wbmod.html). Béniguel and Hamel (2011) formulated of a wave propagation model for equatorial regions. This global ionospheric scintillation propagation model (GISM) aims to estimate various radio propagation effects including phase and amplitude scintillation. The GNSS receiver tracking performance during severe scintillation conditions can be assessed by the analysis of receiver phase-locked-loop (PLL) jitter (Conker et al., 2003; Sreeja et al., 2011; Aquino and Sreeja, 2013, Prikryl et al., 2013a). Another method to mitigate the effect of ionospheric scintillation using TEC (total electron content) at $1 \mathrm{~Hz}$ was described by Tiwari and Strangeways (2015).

At high latitudes, statistical characterization and climatology of scintillation of GPS signals show prevalence of phase over amplitude scintillation (Spogli et al., 2009; Li et al., 2010; Prikryl et al., 2011a, b, 2013b; Jiao et al., 2013; Moen et al., 2013). The general lack of amplitude scintillation ( $S_{4}$ index) at high latitudes has been attributed to a commonly used filter to detrend high-rate GPS data when amplitude and phase scintillation indices $S_{4}$ and $\sigma_{\Phi}$ (Beach, 2006; Forte, 2007) are computed. Different filters and indices have been proposed to alleviate this problem (Forte, 2005; Zhang et al., 2010; Mushini et al., 2012). However, the phase scintillation index $\sigma_{\Phi}$ has been widely used to characterize phase scintillation and is found to be correlated with proxy phase scintillation indices that can be obtained from $1 \mathrm{~Hz}$ data by geodetic-quality GPS receivers (Ghoddousi-Fard et al., 2013). In this paper we use phase scintillation index $\sigma_{\Phi}$ obtained by the Canadian High Arctic Ionospheric Network (CHAIN) to extend the initial phase scintillation climatology study (Prikryl et al., 2011a) over a period of 6 years, from 2008 to 2013.

\section{Instruments and data}

Phase scintillation data used in this study were collected by ten specialized GISTMs of CHAIN (http://chain.physics. unb.ca/chain) (Jayachandran et al., 2009). CHAIN GISTMs and ionosondes are distributed in the auroral oval, cusp and the polar cap (Fig. 1). A table of CHAIN stations' geographic 
and geomagnetic coordinates of stations can be found in Prikryl et al. (2011a).

The NovAtel OEM4 GSV 4004B dual-frequency GPS receivers (Van Dierendonck and Arbesser-Rastburg, 2004), with special firmware specifically configured to record the power and phase of the L1 signal at a $50 \mathrm{~Hz}$ sampling rate, compute the ionospheric total electron content (TEC) using both L1 and L2 signals, the amplitude scintillation index $S_{4}$ and the phase scintillation index $\sigma_{\Phi}$. The phase scintillation index $\sigma_{\Phi}$ is the standard deviation of the detrended phase using a filter in the receiver with a $0.1 \mathrm{~Hz}$ cutoff frequency.

To characterize the space weather climate, additional parameters such as Kp index and solar wind measurements are used. The Kp index of geomagnetic activity that has been derived and distributed by the German Research Centre for Geosciences was obtained through http://wdc.kugi.kyoto-u. ac.jp/kp/. Solar wind data are obtained from the Goddard Space Flight Center Space Physics Data Facility OMNIWeb (http://omniweb.gsfc.nasa.gov/). This data set provides time series of magnetic field and plasma parameters projected to the nose of the Earth's bow shock to accommodate for propagation delays from the spacecraft. In this paper, hourly values of the IMF $B_{Y}$ and $B_{Z}$ components are used to investigate scintillation dependence on the polarity of the IMF components. Other solar wind parameters are used to identify arrival times of high speed streams (HSSs). Following the criteria of Prikryl et al. (2012), co-rotating interaction regions (CIRs) at the leading edges of HSSs were determined. For arrival times of interplanetary coronal mass ejections (ICMEs), a catalogue of near-Earth ICMEs (Richardson and Cane, 2010) that is updated at http://www.srl.caltech. edu/ACE/ASC/DATA/level3 was used.

\section{Phase scintillation climatology}

The phase scintillation occurrence is represented as a function of magnetic local time (MLT) and the altitude-adjusted corrected geomagnetic (AACGM) latitude (Baker and Wing, 1989; Shepherd et al., 2014). In this paper, the scintillation data are merged on a grid with bins of $1 \mathrm{~h} \mathrm{MLT} \times 2.5^{\circ} \mathrm{CGM}$ latitude. Although the altitude of ionospheric irregularities causing scintillation varies and is unknown in general, we assume ionospheric pierce point (IPP) at $350 \mathrm{~km}$ altitude. The scintillation occurrence is simply defined as $100 \times N\left(\sigma_{\Phi}>0.1\right) / N_{\text {tot }}$, where $N$ is the number of cases when phase scintillation index exceeded a given threshold and $N_{\text {tot }}$ is the total number of data points with IPPs in the bin. Bins with sparse statistics are removed and marked as grey areas in the plots as done by other authors (Spogli et al., 2009). Here we adopted a relatively low $\sigma_{\Phi}$ threshold of 0.1 radians (weak scintillation). To minimize the multipath effect, only elevations exceeding $30^{\circ}$ are used. The values of $\sigma_{\Phi}$ are projected to the vertical to account for geometrical effects on the measurements made at different elevation angles (Spogli et al., 2009; their Eq. 1). The scope of the present paper does not allow enough space to consider higher thresholds that would specifically characterize moderate and strong scintillation. For typical scintillation strength in various regions of the high-latitude ionosphere including cusp, auroral oval and polar cap, we refer the reader to case studies (e.g., Jin et al., 2014; Prikryl et al., 2015a, b, c). It should be noted that proxy scintillation indices such as the rate of TEC index (ROTI) (Jacobsen and Dähnn, 2014) and disturbance ionosphere index (DIX) (Jakowski et al., 2012) could be used instead of $\sigma_{\Phi}$ to map scintillation with comparable results. Also, GPS climatology of scintillation and TEC in the Southern Hemisphere (Spogli et al., 2013) and interhemispheric comparison is of interest for future studies.

\subsection{Scintillation occurrence dependence on geomagnetic activity}

Figure $2 \mathrm{a}$ and $\mathrm{b}$ show the mean occurrence of phase scintillation with $\sigma_{\Phi}$ exceeding 0.1 radians as a function of MLT and magnetic latitude for 1858 quiet and 334 disturbed days selected over a period of 6 years. The scintillation statistics were divided into two parts, geomagnetically quiet and disturbed days, using a 3-hourly Kp index level over $24 \mathrm{~h}$ with a disturbed day defined as having a $\mathrm{Kp}$ index greater than 2 for more than $60 \%$ of the day. Superposed on the maps are the boundaries of the Feldstein statistical auroral oval for a quiet and moderately disturbed conditions (Feldstein and Starkov, 1967; Holzworth and Meng, 1975). The control parameter for the Feldstein model is the index $Q$ (IQ) ranging from 0 to 6 for quiet to active oval. The scintillation occurrence during quiet conditions is confined in a smaller and narrower area with relatively low percentages. In general, under disturbed conditions, the scintillation occurrence is at least $10 \%$ higher and the scintillation area becomes larger and broader when the auroral oval expands. In both cases, as previously observed (Spogli et al., 2009; Prikryl et al., 2011), there are two principal regions where scintillation occurs most frequently: the cusp with extension into dayside polar cap and the nightside auroral oval. For the disturbed days, the area of enhanced scintillation occurrence extends equatorward of the statistical oval particularly in the post-midnight to noon sector. This enhancement can be attributed to the equatorward shift of the active auroral oval with a possible addition of sub-auroral polarization streams (SAPS) and stormenhanced density (SED) that are more frequent during disturbed periods (Foster and Burke, 2002; Foster et al., 2004; Clausen et al., 2012; Prikryl et al., 2015c).

To consider the impact of specific solar wind disturbances on scintillation occurrence, we compiled 137 days of major CIR/HSSs arrival (stream maximum velocity $V_{\text {MAX }}$ exceeding $500 \mathrm{~km} \mathrm{~s}^{-1}$ ) and 55 start days of ICME disturbances, for which the geomagnetic storm intensity characterized by Dst index was less than $-30 \mathrm{nT}$. Because some of these time arrivals may occurred at later UT hours on the day of arrival (day 0 ), we added the following day (day 1) to the statistics to 

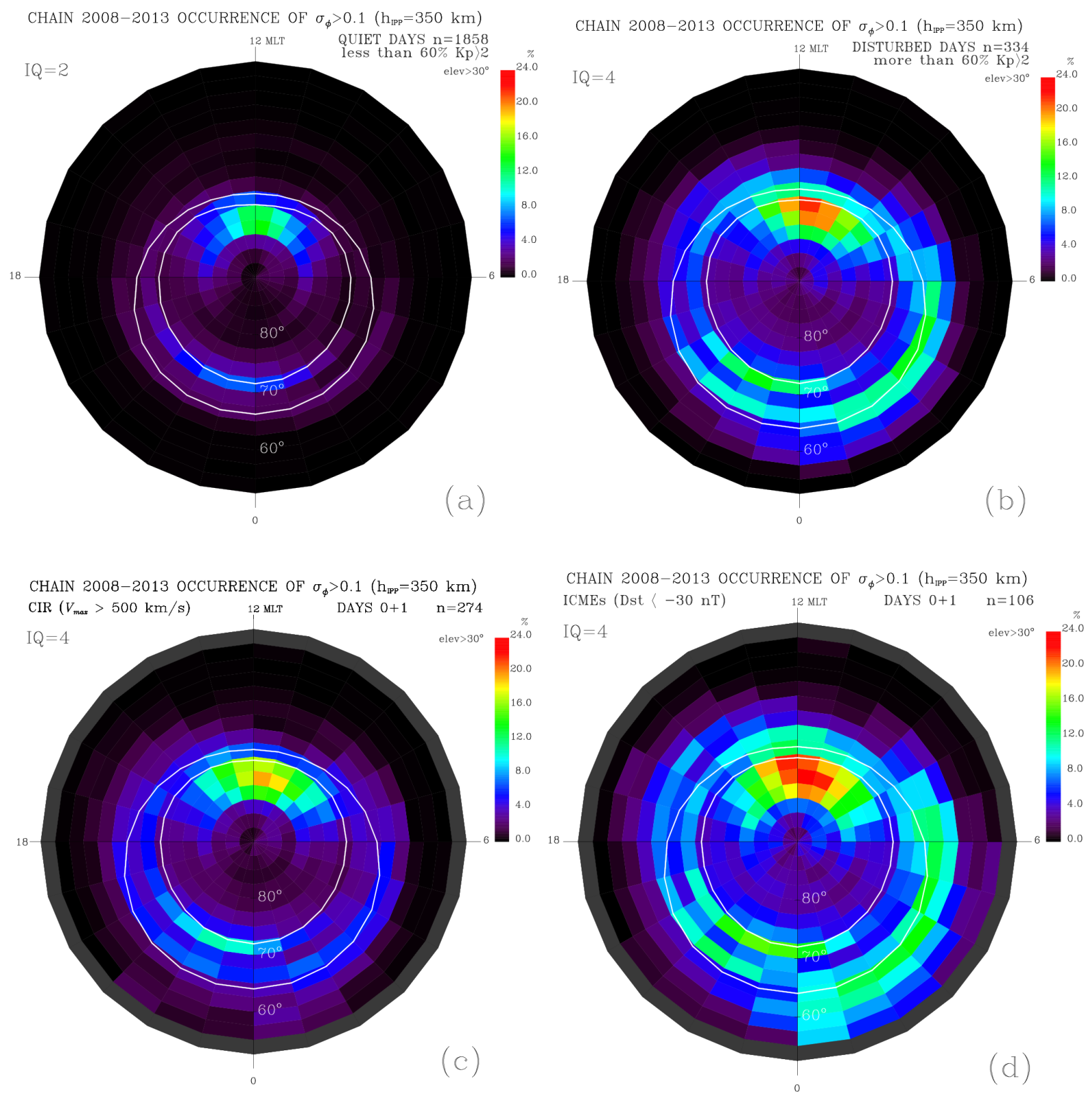

Figure 2. The 2008-2013 phase scintillation occurrence maps for geomagnetically (a) quiet and (b) disturbed days, and for (c) CIR/HSS and (d) ICME days.

compute the mean occurrence of phase scintillation for CIRs and ICMEs (Fig. 2c and d). The scintillation occurrence for ICME days is significantly higher than for CIR days as previously shown using a superposed epoch analysis (Prikryl et al., 2014). In particular, there is significantly higher scintillation occurrence equatorward of the statistical auroral oval. This can be attributed to most intense events when auroral oval expanded further equatorward and SAPS/SED events occurred (Prikryl et al., 2013b, 2015c), which is more often the case during ICME disturbances. On the other hand, CIR/HSSs are known to be permeated with high-amplitude solar wind Alfvén waves coupling to the dayside magne- topause and producing copious patches (Prikryl et al., 1999, 2015a). Polar patches are the main cause of scintillation in the polar cap but also in the nightside auroral oval as they evolve into auroral blobs (Jin et al., 2014).

The sub-auroral scintillation was less likely during the past solar minimum 2008-2009 (Prikryl et al., 2011), even when extended by 1 more year to 2008-2010 (Prikryl et al., 2012). In the present data analysis we included 3 more years spanning the rising solar activity up to the current, though relatively low, solar maximum. Figure $3 \mathrm{a}-\mathrm{d}$ show yearly maps of the mean occurrence of phase scintillation for disturbed days from 2010 to 2013. Approaching the solar maximum, 

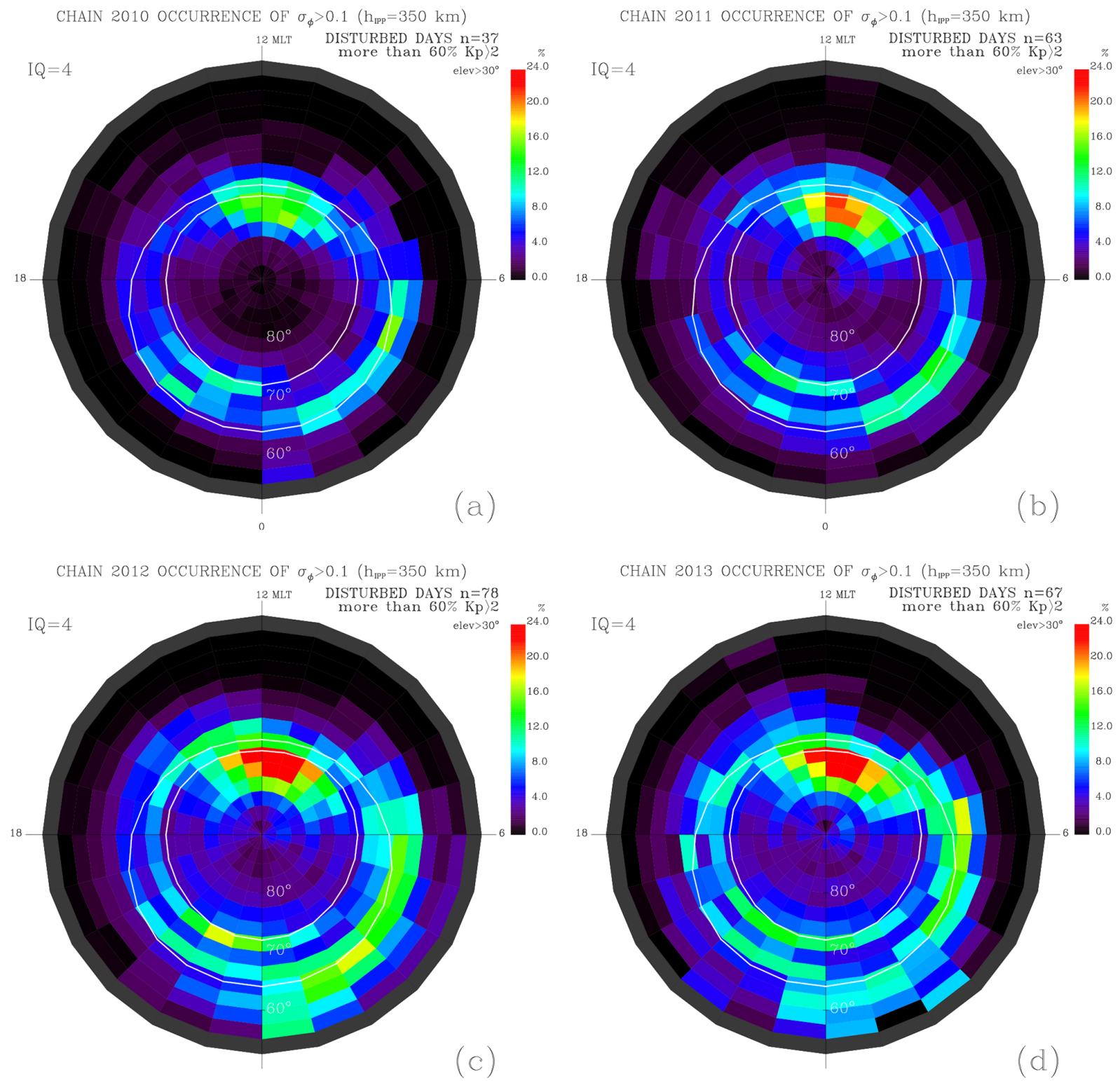

Figure 3. The yearly phase scintillation occurrence maps for geomagnetically disturbed days.

the scintillation occurrence progressively increased in all regions, and the total area of enhanced scintillation occurrence extended further equatorward and poleward into the polar cap. As already stated for ICME days, this is a result of more frequent expansion of the auroral oval during intense auroral events that can include SAPS events and increased activity in the polar cap including the tongue of ionization (TOI) that is drawn from dense SED plasma producing patches of enhanced plasma density. In case studies, weak-to-moderate scintillation was found at sub-auroral latitudes, collocated with SAPS, and events of moderate-to-strong scintillation associated with TOI and polar patches were observed in the polar cap (Prikryl et al., 2013b, 2015a, b, c).

\subsection{Seasonal dependence of scintillation occurrence}

The scintillation data are divided into four 3-month intervals that are approximately centered on equinoxes and solstices to examine the seasonal variation of the mean scintillation occurrence maps (Fig. 4a-d). Regions identified as cusp (cu), polar cap (pc), nightside auroral oval (au) and postmidnight auroral/subauroral region (sa) with possible contribution from SAPS are outlined in gray dashed lines in Fig. 4a. The cu sector stretches between 9 and 15 MLT, and between 72.5 and $80^{\circ} \mathrm{CGM}$ latitude, the pc region is above $75^{\circ} \mathrm{CGM}$ latitude with exclusion of the cusp, the au sector lies between 19 and 2 MLT, and between 65 and $75^{\circ} \mathrm{CGM}$ latitude, while the sa belt lies between 0 and 7 MLT and is 

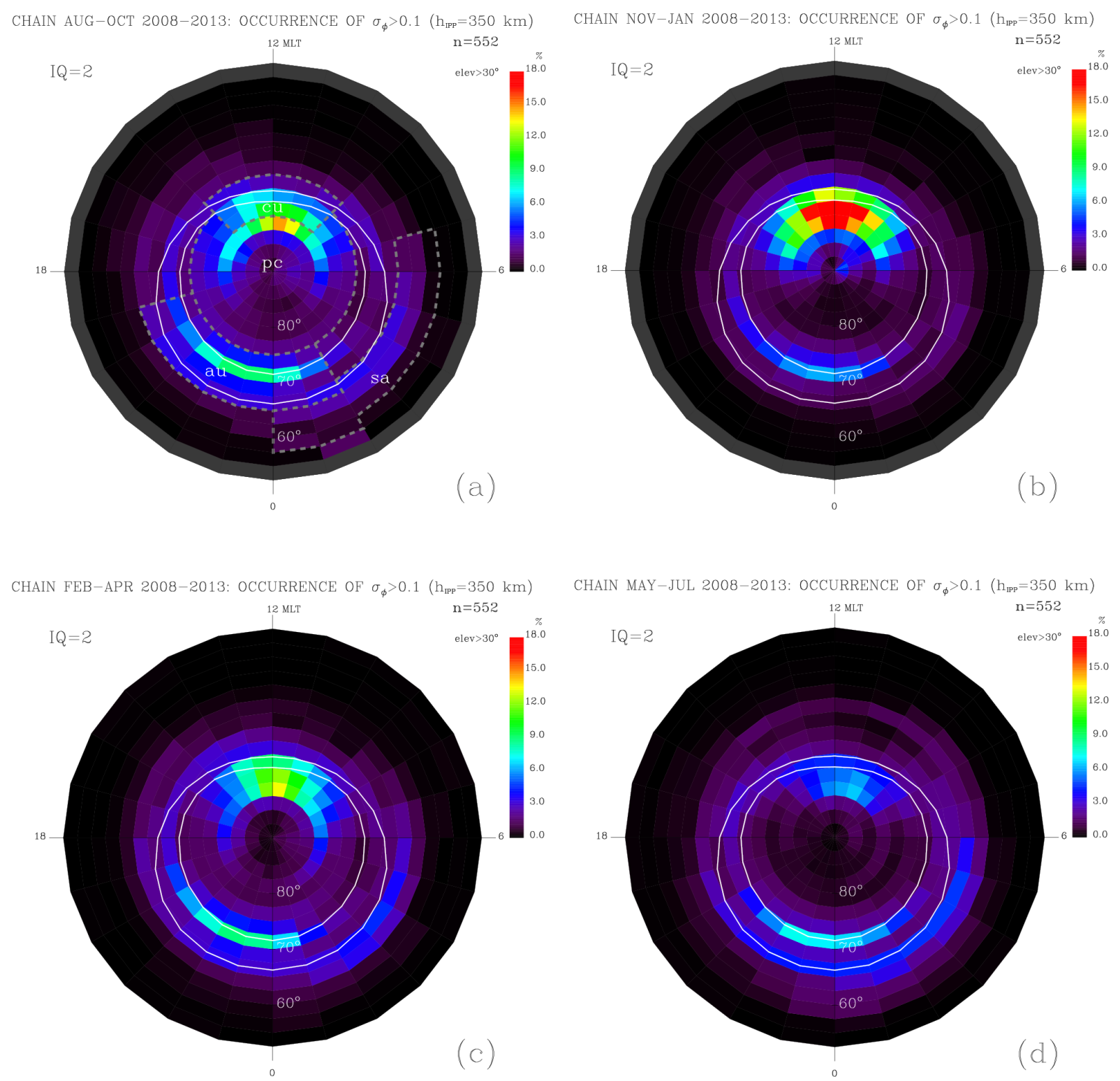

Figure 4. Phase scintillation occurrence maps $\left(h_{\mathrm{IPP}}=350 \mathrm{~km}\right)$ for $(\mathbf{a})$ autumn, (b) winter, (c) spring and (d) summer. Regions identified as cusp (cu), polar cap (pc), nightside auroral oval (au) and post-midnight auroral/subauroral region (sa) are outlined in gray dashed lines in panel (a).

defined here by two pairs of latitude ranges between 57.5 and $65.0^{\circ} \mathrm{CGM}$ and between 60.0 and $67.5^{\circ} \mathrm{CGM}$ latitude. The highest scintillation occurrence is observed in the cusp and the dayside polar cap in the winter months (Fig. 4b). The scintillation occurrence in the nightside auroral oval, at the poleward edge in particular, is highest in autumn (Fig. 4a) and spring (Fig. 4c). The scintillation region in the nightside auroral oval shows a clear dawn-dusk asymmetry (predominance of scintillation in pre-midnight hours) in all seasons. The sa belt of scintillation is most likely associated with fast convection in the expanded dawn convection cell with possi- ble contribution from SAPS is noticeable in all seasons but is weakest in the winter (Fig. 4b).

So far we assumed an IPP altitude of $350 \mathrm{~km}$ for scintillation mapping. This is plausible in the polar cap and cusp when considering polar cap patches and convection of irregularities. However, the energetic particles that cause aurora, discrete aurora in particular, produce maximum ionization at much lower heights. For mapping the scintillation caused by bright aurora, an IPP height of $110 \mathrm{~km}$ has been used (e.g., Prikryl et al., 2013b, 2015a). This results in IPPs that are closer to GPS receivers and shrinks the latitudinal and longitudinal range of IPPs. The grid cell latitude width of $2.5^{\circ}$ is 

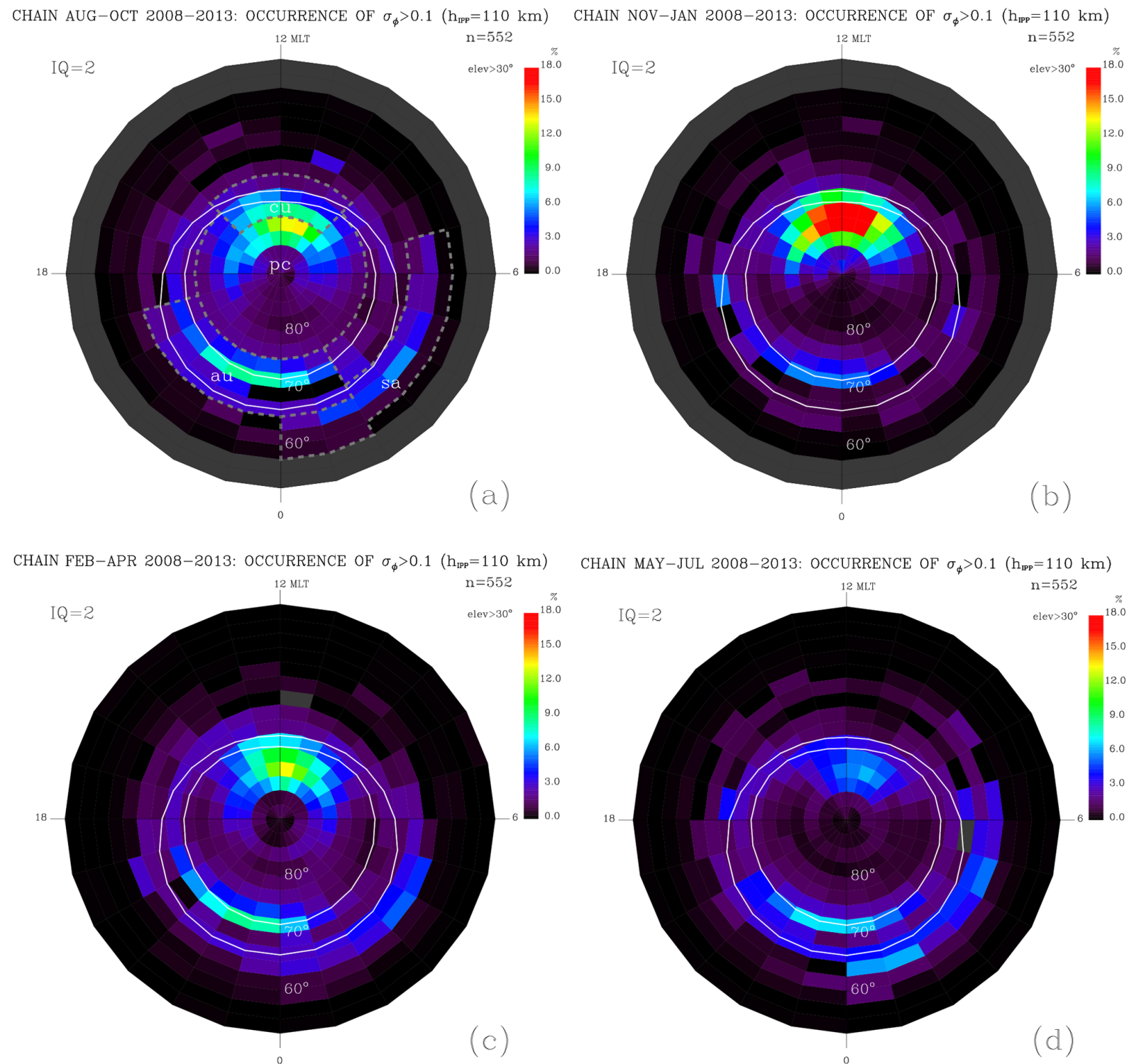

CHAIN MAY-JUL 2008-2013: OCCURRENCE OF $\sigma_{\phi}>0.1\left(\mathrm{~h}_{\mathrm{IPP}}=110 \mathrm{~km}\right)$

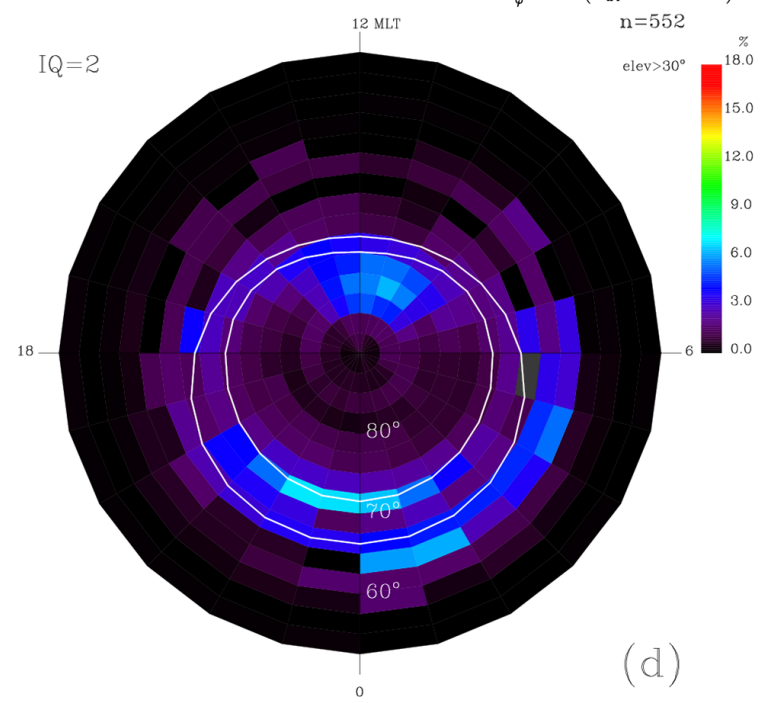

Figure 5. Phase scintillation occurrence maps $\left(h_{\mathrm{IPP}}=110 \mathrm{~km}\right)$ for $(\mathbf{a})$ autumn, $(\mathbf{b})$ winter, $(\mathbf{c})$ spring and $(\mathbf{d})$ summer.

fairly wide but the mapping at $110 \mathrm{~km}$ will significantly redistribute the IPPs in magnetic latitude and MLT when compared with mapping at $350 \mathrm{~km}$. With a small number of receivers, the mapping at $110 \mathrm{~km}$ will result in some gaps in latitude coverage or reduced statistical samples due to small number of data points in grid cells between widely spaced receivers. This is the case particularly in the auroral oval that was, until 2013, covered only by two CHAIN receivers in Edmonton and Sanikiluaq (Fig. 1).

Figure 5a-d show the scintillation occurrence maps for 3month intervals assuming $h_{\mathrm{IPP}}=110 \mathrm{~km}$. When compared with corresponding maps for $h_{\mathrm{IPP}}=350 \mathrm{~km}$ (Fig. 4a-d), some of the occurrence shifted poleward from the cusp area (defined for $h_{\mathrm{IPP}}=350 \mathrm{~km}$; Fig. 4a) and filled a larger proportion of the polar cap area. In the nightside auroral oval, similar poleward shift of scintillation occurrence is discernible although the latitude peak in scintillation occurrence remains within the au area previously selected (Fig. 4a). The scintillation occurrence drops significantly in the latitude band between 67.5 and $75^{\circ} \mathrm{CGM}$ that is approximately centered between the latitudes of receivers in Iqaluit and Sanikiluaq. When mapping IPPs at $h_{\mathrm{IPP}}=110 \mathrm{~km}$, there is a reduction of data points at that latitude. Because of low statistical significance of the computed scintillation occurrence in some grid cell the values are rejected and the grid cells are shown in grey shading. However, the change of the mapping height from 350 to $110 \mathrm{~km}$ does not significantly affect the results of seasonal variations when comparing Figs. 4 and 5 as discussed below. 

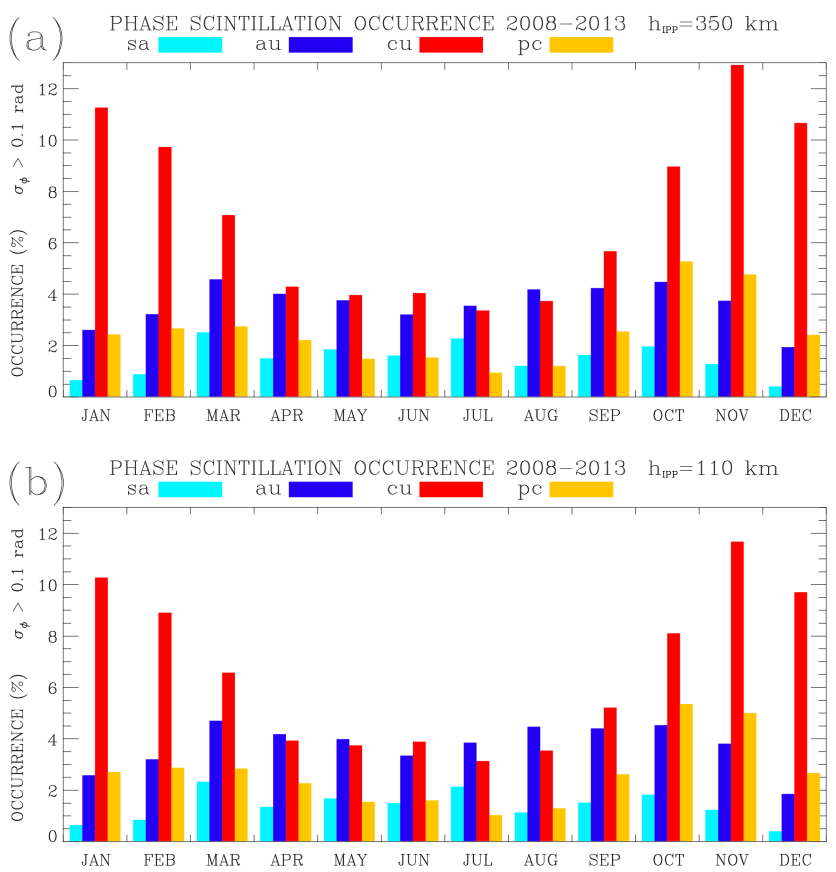

Figure 6. Monthly variation of phase scintillation occurrence in cu, au, pc and sa sectors for (a) $h_{\text {IPP }}=350 \mathrm{~km}$ and (b) $h_{\text {IPP }}=110 \mathrm{~km}$.

To better resolve differences in seasonal dependence of scintillation in cu, pc, au and sa regions the data are grouped by month and averaged over the four regions defined by AACGM latitude and MLT as indicated by grey dashed lines in Figs. 4a and 5a. Figure 6a and b show monthly variations of the mean phase scintillation occurrence in these regions for mapping IPPs at 350 and $110 \mathrm{~km}$, respectively. The au scintillation (shown in dark blue) shows a semiannual oscillation with equinoctial maxima known to be associated with the occurrence of aurora, while the scintillation occurrence in the cu (shown in red) is the highest in late autumn and winter and low in summer, with the maximum in November and the minimum in July. The monthly variation of scintillation occurrence in the polar cap (shown in yellow) is very similar to that observed in the cusp, although it is much reduced in amplitude due to averaging over a large area (pc) with the strongest contribution from the dayside polar cap and the cusp proper, considering quite variable boundary between the $\mathrm{cu}$ and $\mathrm{pc}$ sectors. The mean scintillation occurrence is very low in the sa sector. Similarly to the au sector, it has a minimum in winter and poorly defined maxima around equinoxes, with an anomalously high value in July.

From comparing Fig. 6a and b, we can conclude that the choice of the IPP height in mapping does not significantly affect the results for seasonal variations obtained for selected magnetic latitude and MLT except for small differences in amplitude. In the cu region, the amplitude of annual variation of scintillation occurrence is larger for $h_{\mathrm{IPP}}=350 \mathrm{~km}$. In the pc, au and sa regions the seasonal variations are about the same for both values of $h_{\mathrm{IPP}}$.

\subsection{Scintillation occurrence dependence on the IMF orientation}

The magnetosphere responds to a number of solar wind plasma parameters and a variety of coupling functions (Newell et al., 2007) have been introduced to understand and predict the state of the magnetosphere and, ultimately, the magnetosphere-ionosphere-thermosphere (MIT) system. While a single parameter does not suffice to describe the complex MIT coupling process, the IMF orientation, and the IMF $B_{Z}$ component in particular, has been frequently singled out as the most geo-effective parameter controlling the merging process (Dungey, 1961). The IMF $B_{Z}$ component has been known to control the occurrence of aurora, the dayside merging and its ionospheric signatures in the cusp, the production of polar patches and the occurrence of sunaligned arcs in the polar cap and the sub-auroral ionospheric dynamics including the SAPS and SED phenomena. These are the regions (Fig. 4a) that are identified with enhanced phase scintillation.

First attempts to relate and correlate the high-latitude scintillation occurrence with the IMF orientation, particularly the polarity of the IMF $B_{Z}$, clearly indicated its importance in controlling the scintillation occurrence level ( $\mathrm{Li}$ et al., 2010; Alfonsi et al., 2011; Aquino and Sreeja, 2013). Li et al. (2010) also investigated the influence of the IMF $B_{Y}$ highlighting the dawn-dusk asymmetry of the scintillation response. To further investigate scintillation dependence on the IMF $B_{Y}$ and $B_{Z}$, we use hourly values of the magnetic field components in geocentric solar magnetospheric (GSM) coordinate system obtained from the OMNIWeb database over the period 2008-2013. Instead of simply plotting all values of $\sigma_{\Phi}$ versus corresponding values of IMF $B_{Z}$ (Aquino and Sreeja, 2013), which would result in a very dense plot, Fig. 7a shows the occurrence number of $\sigma_{\Phi}$ values in bins of 0.05 radians $\times 1 \mathrm{nT}$ combining the data from all CHAIN stations, i.e., all data points/IPPs at all latitudes and longitudes covered by CHAIN. The distributions of occurrence number as a function of $B_{Z}$ are fitted with a Gaussian curves for each $\sigma_{\Phi}$ interval and the centers of the Gaussians are shown by the yellow line. The distributions of the occurrence number across negative and positive values of IMF $B_{Z}$ are skewed towards negative $B_{Z}$ values except for $\sigma_{\Phi}<0.1$ radians. The percentage of negative $B_{Z}$ values for $\sigma_{\Phi}$ exceeding given thresholds are shown on the left. This shows that phase scintillation preferentially occurs when IMF $B_{Z}<0$. In contrast, the distributions of phase scintillation occurrence number with IMF $B_{Y}$ (Fig. 7b) are relatively symmetric or only slightly skewed toward negative values of $B_{Y}$.

Figure $8 \mathrm{a}$ and $\mathrm{b}$ show maps of the mean occurrence of phase scintillation $\sigma_{\Phi}>0.1$ for IMF $B_{Z}>+3 \mathrm{nT}$ and $B_{Z}<-3 \mathrm{nT}$, respectively. Here the scintillation occur- 

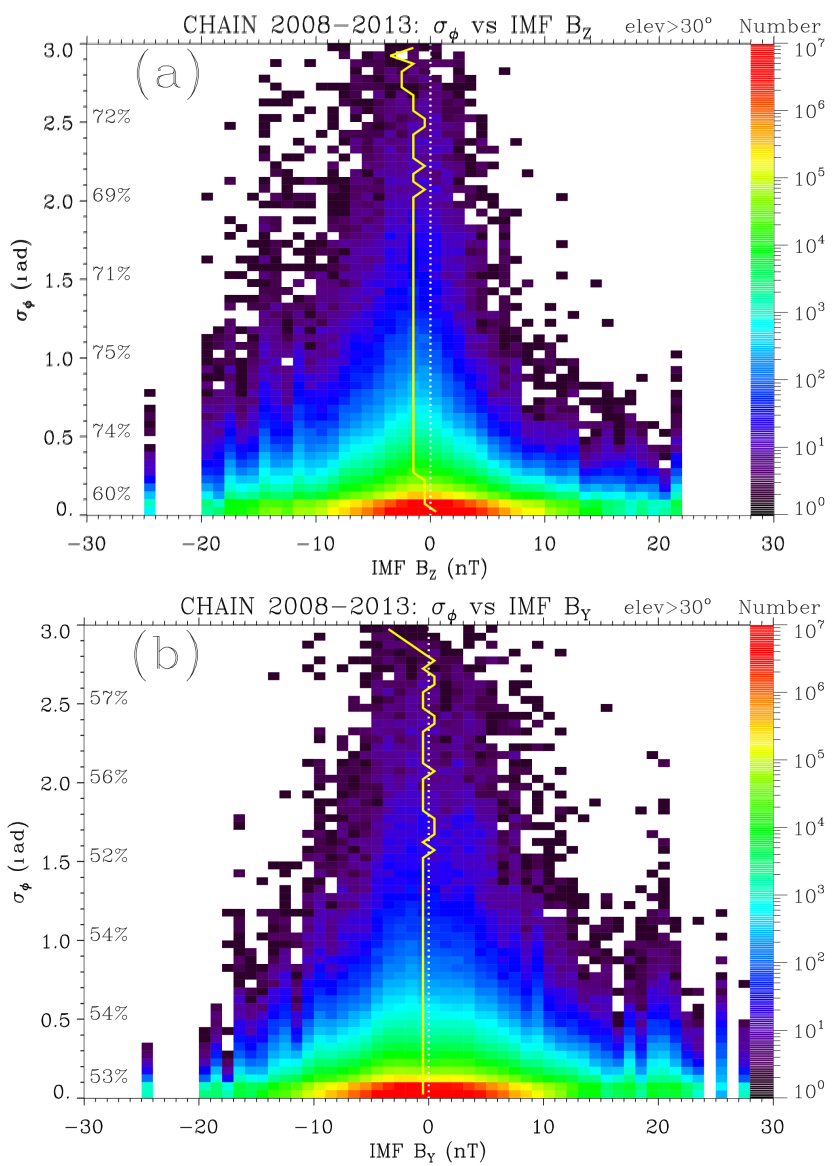

Figure 7. The phase scintillation occurrence dependence on the IMF (a) $B_{Z}$ and (b) $B_{Y}$. The percentages of negative $B_{Z}$ or $B_{Y}$ values for $\sigma_{\Phi}$ exceeding given thresholds are shown on the left. The centers of Gaussian fits to distributions of occurrence number as a function of $B_{Z}$ or $B_{Y}$ for each $\sigma_{\Phi}$ interval are shown by the yellow line.

rence for IMF $B_{Z}>+3 \mathrm{nT}$ is defined as $100 \times N\left(\sigma_{\Phi}>0.1\right.$ and $\left.B_{Z}>+3 \mathrm{nT}\right) / N_{\text {tot }}\left(B_{Z}>+3 \mathrm{nT}\right)$ and similarly for IMF $B_{Z}<-3 \mathrm{nT}$, i.e., the scintillation data sets are selected by the signed mean hourly value of the IMF $B_{Z}$ to obtain $N_{\text {tot }}$ of IPPs (for the same UT hour) that fall in a given bin $\left(1 \mathrm{hMLT} \times 2.5^{\circ} \mathrm{CGM}\right.$ latitude). In other words, when computing the scintillation occurrence for the case of $B_{Z}<-3 \mathrm{nT}, N_{\text {tot }}$ is the number of $\sigma_{\Phi}$ measurements associated with the latter condition, i.e., excluding IPPs in the same grid cell for which $B_{Z} \geq-3 \mathrm{nT}$. We chose arbitrary thresholds of -3 and $+3 \mathrm{nT}$ to characterize strongly southward or northward conditions as opposed to a threshold of $0 \mathrm{nT}$. The latter does not sufficiently discriminate between the two IMF conditions of interest.

For IMF $B_{Z}>+3 \mathrm{nT}$ (Fig. 8a), scintillation occurrence in the auroral oval is low but it persists at a relatively high level in the cusp and the dayside polar cap, extending more than 12 MLT h from dawn to dusk. The dusk-side and dawn-side scintillation is likely caused by sun-aligned arcs that tend to occur either in the dusk-side or dawn-side of the polar cap (Valladares et al., 1994). For IMF $B_{Z}<-3 \mathrm{nT}$ (Fig. 8b), the scintillation is enhanced in the expanded auroral oval and even at sub-auroral latitudes, which is similar to the case of ICMEs (Fig. 2d) and geomagnetically disturbed days particularly in 2012 and 2013 (Fig. 3c and d). However, scintillation occurrence is highest in the cusp from where scintillation associated with TOIs and/or patches extends into the central polar cap.

The dawn-dusk asymmetry in the polar cap is controlled by the polarity of IMF $B_{Y}$. Figure $8 \mathrm{c}$ and d show maps of the mean occurrence of phase scintillation $\sigma_{\Phi}>0.1$ for IMF $B_{Y}>+3 \mathrm{nT}$ and $B_{Y}<-3 \mathrm{nT}$, respectively. The regions of phase scintillation occurrence in the cusp and polar cap are preferentially shifted toward dawn for IMF $B_{Y}>+3 \mathrm{nT}$ and toward dusk for IMF $B_{Y}<-3 \mathrm{nT}$. This is caused by the dawn-dusk asymmetry in the location of sun-aligned arcs and TOIs that are observed preferentially during conditions of IMF $B_{Z}>0$ and $B_{Z}<0$, respectively (Prikryl et al., 2015a). To separate these two cases and to show that the relevant scintillation occurrence is caused by one or the other phenomenon, the scintillation data are more strictly limited by using IMF $B_{Z}$ thresholds of +3 or $-3 \mathrm{nT}$ in addition to splitting the data by the polarity of the IMF $B_{Y}$ (Fig. 9).

For IMF $B_{Z}<-3 \mathrm{nT}$, enhanced scintillation in the cusp that is extended into the dawn-side polar cap for $B_{Y}>+3 \mathrm{nT}$ (Fig. 9a) and into the dusk-side polar cap for $B_{Y}<-3 \mathrm{nT}$ (Fig. 9b) is caused by TOI irregularities, namely polar cap patches. In both cases, there is much enhanced scintillation occurrence in the expanded auroral oval and subauroral regions because of strongly southward IMF. For IMF $B_{Z}>+3 \mathrm{nT}$, scintillation occurrence remains highest in the cusp but is very low in the auroral oval and subauroral regions. In the polar cap, the scintillation extends dawnward for $B_{Y}>+3 \mathrm{nT}$ (Fig. 9c) and duskward for $B_{Y}<-3 \mathrm{nT}$ (Fig. 9d), as expected for the dependence of occurrence of sun-aligned arcs on the IMF $B_{Y}$.

\section{The shape of scintillation-causing ionospheric irregularities}

Ionospheric scintillation is thought to be caused by irregularities of scale sizes from a few hundred meters to a kilometer, which are less elongated (Fremouw et al., 1985; Wernik et al., 1990) than small-scale irregularities, showing anisotropy characterized by a range of axial ratios (Rino and Owen, 1980; Livingston et al., 1982; Gola et al., 1992) and various shapes from cylindrical to sheet-like, as discussed by these authors and briefly summarized previously (see, e.g., Prikryl et al., 2011). Assuming an IPP height of $350 \mathrm{~km}$, Gola et al. (1992) generated maps of amplitude scintillation as a function of angles between the ray path and the geomagnetic L-shell and the plane of magnetic meridian indicating a predominance of field-aligned irregularities. Prikryl et al. (2011) applied this approach to phase scintillation occurrence based 


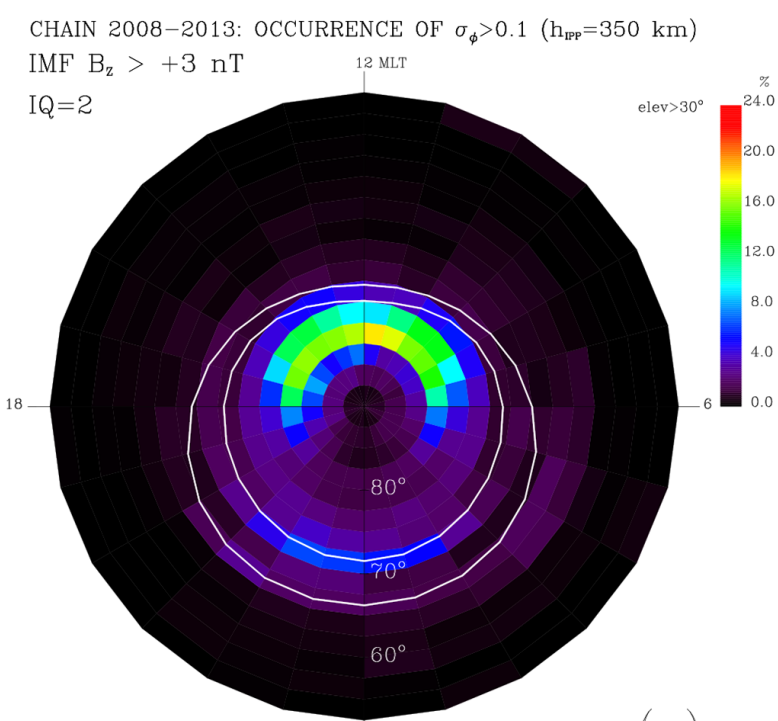

(a)

CHAIN 2008-2013: OCCURRENCE OF $\sigma_{\phi}>0.1\left(h_{\mathbb{P P}}=350 \mathrm{~km}\right)$ IMF $\mathrm{B}_{\mathrm{Y}}>+3 \mathrm{nT}$ 12 MLT

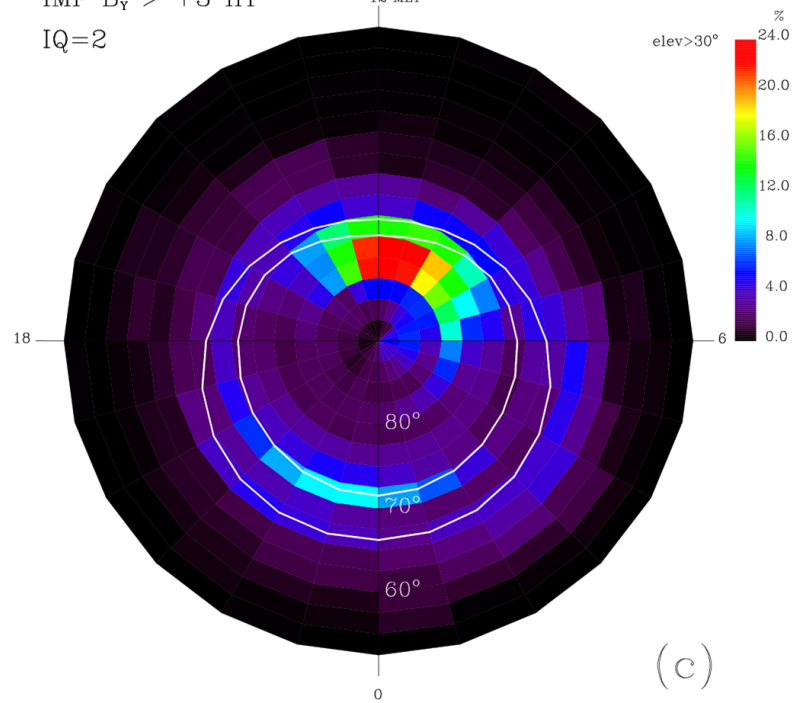

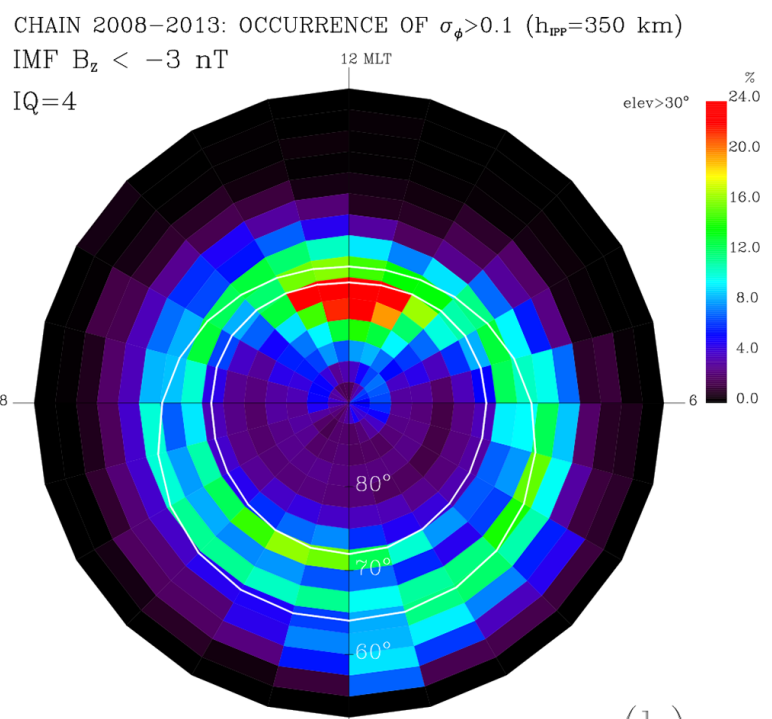

(b)

CHAIN 2008-2013: OCCURRENCE OF $\sigma_{\phi}>0.1 \quad\left(\mathrm{~h}_{\mathrm{IPp}}=350 \mathrm{~km}\right)$ IMF $B_{\mathrm{Y}}<-3 \mathrm{nT} \quad 12 \mathrm{MLT}$

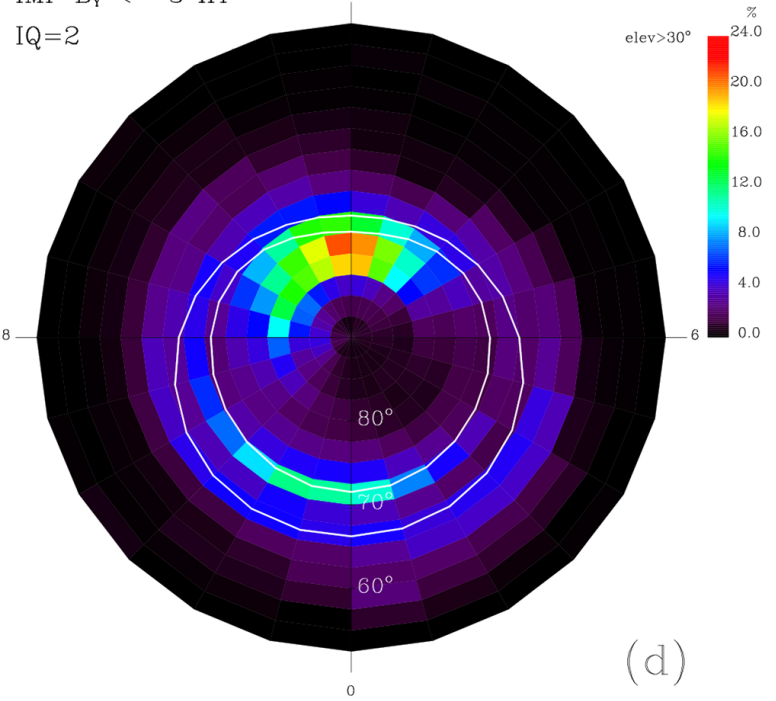

Figure 8. The 2008-2013 phase scintillation occurrence maps for (a) $B_{Z}>+3 \mathrm{nT}$, (b) $B_{Z}<-3 \mathrm{nT}$, (c) $B_{Y}>+3 \mathrm{nT}$ and (d) $B_{Y}<-3 \mathrm{nT}$.

on the first 2 years of CHAIN data with the results that suggested a mixture of field-aligned and L-shell-aligned irregularity shapes. Here we extend this analysis by 4 more years of data.

Figure 10 shows phase scintillation occurrence as a function of off-meridian and off-shell angles that were computed for the receiver-satellite ray at the IPP height $350 \mathrm{~km}$. The data are binned into $5 \times 5^{\circ}$ grid points with the off-shell angle positive for IPPs northward of the receiver and offmeridian angle positive for IPPs eastward of the receiver. High scintillation occurrence at small off-meridian and small off-shell angles, i.e., near magnetic zenith, suggest fieldaligned irregularities. On the other hand, large off-meridian angles along with relatively small off-shell angles indicate Lshell-aligned irregularities. The angle distribution map for all
MLTs and latitudes combined (Fig. 10a) shows a composite of a peak in scintillation occurrence at small angles near magnetic zenith and a broad band of scintillation occurrence at low off-shell angles less than $20^{\circ}$ but a range of off-meridian angles $\pm 60^{\circ}$, suggesting that phase scintillation is caused by a mixture of field-aligned and L-shell oriented irregularities. In comparison, the irregularities causing scintillation in the au region show a large degree of field alignment (Fig. 10b), while the irregularities causing the scintillation in the cu region are L-shell aligned (Fig. 10c). For the dayside (dawn and dusk) auroral oval excluding the cusp, the distributions of off-meridian and off-shell angles (not shown) also indicate strongly field-aligned irregularities. However, for the sa region that includes the post-midnight equatorward edge of the auroral oval and SAPS (Fig. 10d), there is rather low scintil- 

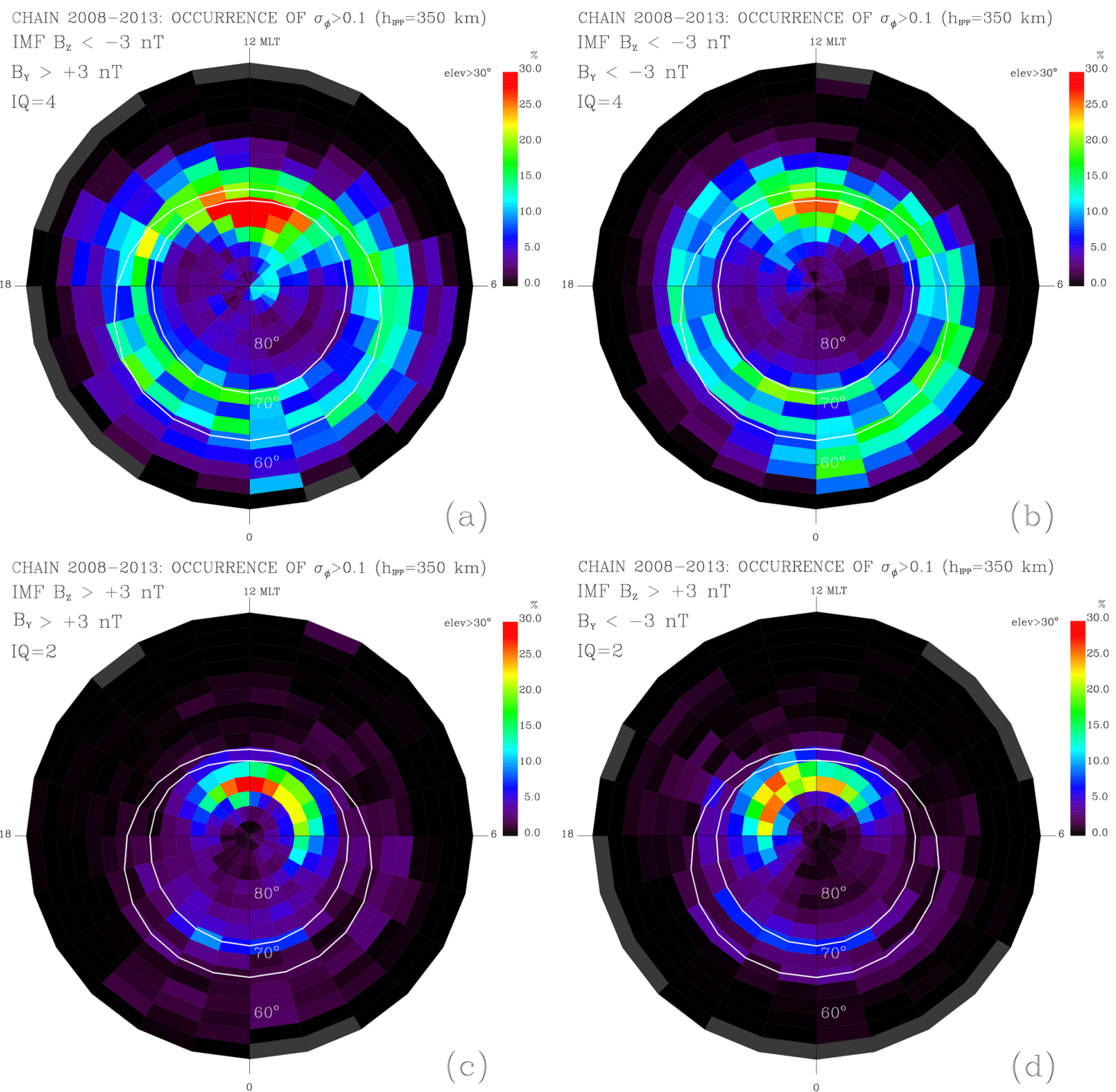

CHAIN 2008-2013: OCCURRENCE OF $\sigma_{\phi}>0.1\left(\mathrm{~h}_{\mathrm{TPP}}=350 \mathrm{~km}\right)$

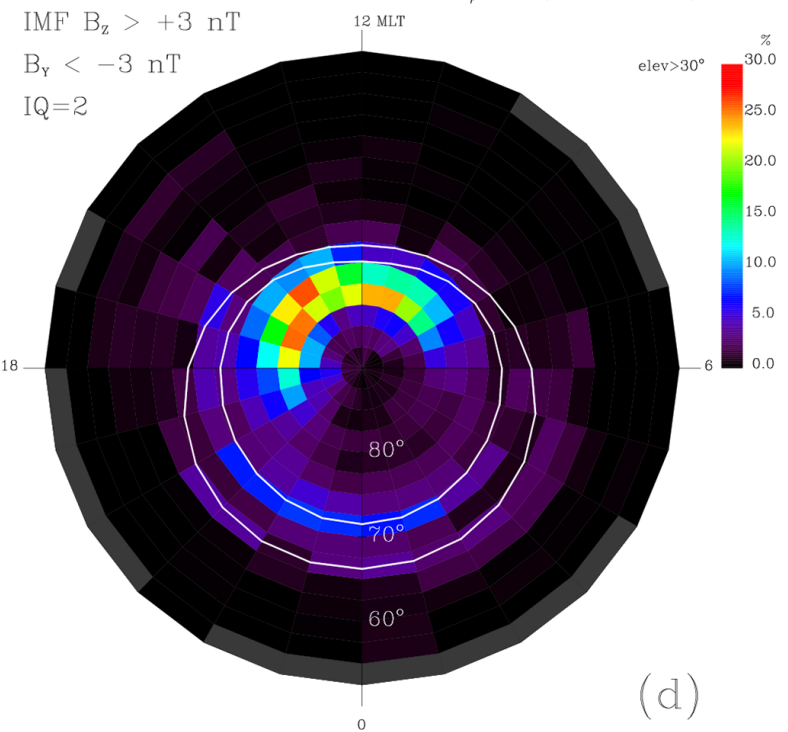

Figure 9. The 2008-2013 phase scintillation occurrence maps for strongly southward $B_{Z}<-3 \mathrm{nT}$ for the cases of (a) $B_{Y}>+3 \mathrm{nT}$ and (b) $B_{Y}<-3 \mathrm{nT}$, and for strongly northward $B_{Z}>+3 \mathrm{nT}$ for the cases of (c) $B_{Y}>+3 \mathrm{nT}$ and (d) $B_{Y}<-3 \mathrm{nT}$.

lation occurrence with a broad peak approximately centered near magnetic zenith. For the dayside subauroral region representing SEDs, we obtained similar results (not shown). The same data analysis was repeated for the IPP height at $110 \mathrm{~km}$, giving very similar results for all regions.

These results are in agreement with the initial results (Prikryl et al., 2011), indicating that scintillation-causing irregularities are more shell aligned in the cusp than in the nightside auroral oval where there is a higher percentage of scintillation near the magnetic zenith suggesting fieldaligned irregularities. However, it should be noted that, at high latitudes in the cusp, the observations (IPPs) are mostly confined to the south of the receiver. They are scarce close to magnetic zenith and completely absent poleward of it.

\section{Summary and conclusions}

The data from 6 years of CHAIN operation have been analyzed to obtain GPS phase scintillation climatology at high latitudes. The period of 2008-2013 included an extended deep solar minimum and the rising phase toward solar maximum of the current solar cycle 24 . The phase scintillation most frequently occurs on the dayside in the cusp, poleward of the cusp in the polar cap and in the nightside auroral oval, particularly at its poleward edge associated with discrete au- 

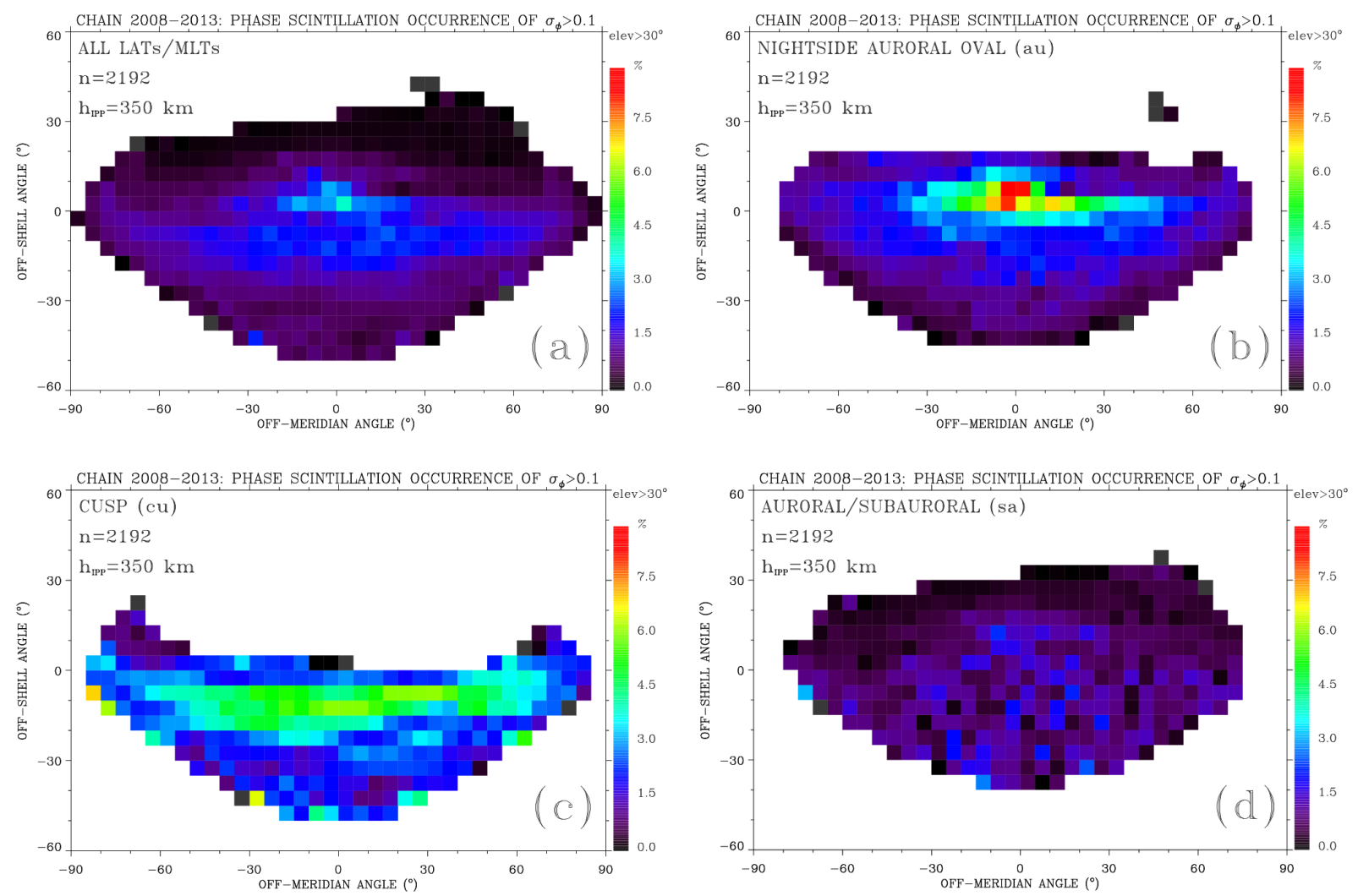

Figure 10. Maps of phase scintillation occurrence as a function of off-meridian and off-shell angles assuming $h_{\mathrm{IPP}}=350 \mathrm{~km}$ for $(\mathbf{a})$ all latitudes and MLTs combined, (b) au, (c) cu and (d) sa.

rora. During geomagnetically disturbed days, the area of enhanced scintillation occurrence extends equatorward of the statistical oval. When the auroral oval expands as a result of southward IMF and ensuing geomagnetic activity, particularly during impacts of coronal mass ejections and highspeed solar wind streams, phase scintillation increasingly occurs near the equatorward border of the post-midnight auroral oval where moderate-to-strong scintillation was previously shown to be collocated with intense return convection. Scintillation may be collocated with subauroral polarization streams and storm-enhanced density events. With rising solar activity from the solar minimum to solar maximum, the yearly maps of phase scintillation occurrence show gradual increase in occurrence and an expansion of enhanced scintillation both poleward and equatorward from the statistical auroral oval. Examining the seasonal variations, the scintillation occurrence in the nightside auroral oval shows semiannual variation with equinoctial maxima known to be associated with auroras. The seasonal variation in the cusp and polar cap is dominated by an annual cycle maximizing in the autumn and winter months with a minimum in summer. A strong dependence of scintillation occurrence on the IMF orientation is marked by increased scintillation occurrence in the cusp, expanded auroral oval and at subauroral latitudes for strongly southward IMF. In the polar cap, en- hanced scintillation is collocated with tongue of ionization and/or patches for the southward IMF and with sun-aligned arcs for the northward IMF. Both cases show dawn-dusk asymmetries controlled by the IMF $B_{Y}$ polarity. The observations of phase scintillation occurrence as a function of off-meridian and off-shell angles that are computed for the receiver-satellite ray at the ionospheric pierce point suggest a mixture of magnetic field-aligned and magnetic L-shellaligned irregularities. In the cusp, the irregularities indicate shell alignment while there is a significant component of field-aligned irregularities in the nightside auroral and, to a lesser degree, in the sub-auroral latitudes.

Acknowledgements. Infrastructure funding for CHAIN was provided by the Canada Foundation for Innovation and the New Brunswick Innovation Foundation. CHAIN operation is conducted in collaboration with the Canadian Space Agency (CSA). This work was supported by the Public Safety Geosciences program of the Natural Resources Canada, Earth Sciences Sector (NRCan ESS contribution no. 20140373)

The topical editor H. Kil thanks K. S. Jacobsen and one anonymous referee for help in evaluating this paper. 


\section{References}

Aarons, J.: Global morphology of ionospheric scintillations, Proceedings of IEE, 70, 360-378, 1982.

Aarons, J.: Global positioning system phase fluctuations at auroral latitudes, J. Geophys. Res., 102, 17219-17231, doi:10.1029/97JA01118, 1997.

Aarons J., Lin, B., Mendillo, M., Liou, K., and Codrescu, M.: Global Positioning System phase fluctuations and ultraviolet images from the Polar satellite, J. Geophys. Res., 105, 5201-5213, doi:10.1029/1999JA900409, 2000.

Alfonsi, L., Spogli, L., De Franceschi, G., Romano, V., Aquino, M., Dodson, A., and Mitchell, C. N.: Bipolar climatology of GPS ionospheric scintillation at solar minimum, Radio Sci., 46, RS0D05, doi:10.1029/2010RS004571, 2011.

Aquino, M. and Sreeja, V.: Correlation of scintillation occurrence with interplanetary magnetic field reversals and impact on Global Navigation Satellite System receiver tracking performance, Space Weather, 11, 219-224, doi:10.1002/swe.20047, 2013.

Aquino, M., Andreotti, M., and Dodson, A., and Strangeways, H.: On the Use of Ionospheric Scintillation Indices as Input to Receiver Tracking Models, Adv. Space Res., 40, 426-435, 2007.

Baker, K. B. and Wing, S.: A new magnetic coordinate system for conjugate studies at high latitudes, J. Geophys. Res., 94, 91399143, 1989.

Basu S., MacKenzie, E. M., Basu, Su., Costa, E., Fougere, P. F., Carlson, H. C. Jr., and Whitney, H. E.: $250 \mathrm{MHz} / \mathrm{GHz}$ scintillation parameters in the equatorial, polar, and auroral environments, IEEE J. Sel. Area. Comm., SAC-2, 102-115, 1987.

Basu, S., Basu, S., Sojka, J. J., Schunk, R. W., and MacKenzie, E.: Macroscale modeling and mesoscale observations of plasma density structures in the polar cap, Geophys. Res. Lett., 22, 881-884, doi:10.1029/95GL00467, 1995.

Basu, S., Weber, E. J., Bullett, T. W., Keskinen, M. J., MacKenzie, E., Doherty, P., Sheehan, R., Kuenzler, H., Ning, P., and Bongiolatti, J.: Characteristics of plasma structuring in the cusp/cleft region at Svalbard, Radio Sci., 33, 1885-1899, doi:10.1029/98RS01597, 1998.

Beach, T. L.: Perils of the GPS phase scintillation index $\left(\sigma_{\Phi}\right)$, Radio Sci., 41, RS5S31, doi:10.1029/2005RS003356, 2006.

Beìniguel, Y. and Hamel, P.: A global ionosphere scintillation propagation model for equatorial regions, J. Space Weather Space Clim., 1, A04, doi:10.1051/swsc/2011004, 2011.

Clausen, L. B. N., Baker, J. B. H., Ruohoniemi, J. M., Greenwald, R. A., Thomas, E. G., Shepherd, S. G., Talaat, E. R., Bristow, W. A., Zheng, Y., Coster, A. J., and Sazykin, S.: Large-scale observations of a subauroral polarization stream by midlatitude SuperDARN radars: Instantaneous longitudinal velocity variations, J. Geophys. Res., 117, A05306, doi:10.1029/2011JA017232, 2012.

Conker, R. S., El Arini, M. B., Hegarty, C. J., and Hsiao, T.: Modeling the effects of ionospheric scintillation on GPS/SatelliteBased Augmentation System availability, Radio Sci., 38, 1001, doi:10.1029/2000RS002604, 2003.

Decker, D. T. and Pedersen, T. R.: Downstream Forecasting of Ionospheric Scintillation Based on Trajectory Modeling of In-situ Measurements, American Geophysical Union, Fall Meeting Abstract \# SA51A-0762, 2001.

Dungey, J. W.: Interplanetary magnetic field and auroral zones, Phys. Rev. Lett., 6, 47-48, 1961.
Feldstein, Y. I. and Starkov, G. V.: Dynamics of auroral belt and polar geomagnetic disturbances, Planet. Space Sci., 15, 209-230, 1967.

Forte, B.: Optimum detrending of raw GPS data for scintillation measurements at auroral latitudes, J. Atmos. Sol.-Terr. Phy., 67, 1100-1109, doi:10.1016/j.jastp.2005.01.011, 2005.

Forte, B.: On the relationship between the geometrical control of scintillation indices and the data detrending problems observed at high latitudes, Ann. Geophys.-Italy, 50, 699-706, 2007.

Foster, J. C. and Burke, W. J.: SAPS: A new categorization for sub-auroral electric fields, Eos Trans. AGU, 83, 393-394, doi:10.1029/2002EO000289, 2002.

Foster, J. C., Coster, A. J., Erickson, P. J., Rich, F. J., and Sandel, B. R.: Stormtime observations of the flux of plasmaspheric ions to the dayside cusp/magnetopause, Geophys. Res. Lett., 31, L08809, doi:10.1029/2004GL020082, 2004.

Fremouw, E. J., Secan, J. A., and Lansinger J. M.: Spectral behavior of phase scintillation in the nighttime auroral region, Radio Sci., 20, 923-933, doi:10.1029/RS020i004p00923, 1985.

Ghoddousi-Fard, R., Prikryl, P., and Lahaye, F.: GPS phase difference variation statistics: A comparison between phase scintillation index and proxy indices, Adv. Space Res., 52, 1397-1405, 2013.

Gola, M., Wernik, A. W., Franke, S. J., Liu, C. H., and Yeh, K. C.: Behaviour of HILAT scintillation over Spitsbergen, J. Atmos. Terr. Phys., 54, 1207-1213, 1992.

Holzworth, R. H. and Meng, C.-I.: Mathematical Representation of the Auroral Oval, Geophys. Res. Lett., 2, 377-380, 1975.

Jacobsen, K. S. and Dähnn, M.: Statistics of ionospheric disturbances and their correlation with GNSS positioning errors at high latitudes, J. Space Weather Space Clim., 4, A27, doi:10.1051/swsc/2014024, 2014.

Jakowski, N., Borries, C., and Wilken, V.: Introducing a disturbance ionosphere index, Radio Sci., 47, RS0L14, doi:10.1029/2011RS004939, 2012.

Jayachandran, P. T., Langley, R. B., MacDougall, J. W., Mushini, S. C., Pokhotelov, D., Hamza, A. M., Mann, I. R., Milling, D. K., Kale, Z. C., Chadwick, R., Kelly, T., Danskin, D. W., and Carrano, C. S.: Canadian High Arctic Ionospheric Network (CHAIN), Radio Sci., 44, RS0A03, doi:10.1029/2008RS004046, 2009.

Jiao, Y., Morton, Y. T., Taylor, S., and Pelgrum, W.: Characterization of high-latitude ionospheric scintillation of GPS signals, Radio Sci., 48, 698-708, doi:10.1002/2013RS005259, 2013.

Jin Y., Moen, J. I., and Miloch, W. J.: GPS scintillation effects associated with polar cap patches and substorm auroral activity: direct comparison, J. Space Weather Space Clim., 4, A23, doi:10.1051/swsc/2014019, 2014.

Li, G., Ning, B., Ren, Z., and Hu, L.: Statistics of GPS ionospheric scintillation and irregularities over polar regions at solar minimum, GPS Solut., 14, 331-341, doi:10.1007/s10291-009-0156$\mathrm{x}, 2010$.

Livingston, R. C., Rino, C. L., Owen, J., and Tsunoda, R. T.: The Anisotropy of High-Latitude Nighttime $F$ Region Irregularities, J. Geophys. Res., 87, A12, 10519-10526, doi:10.1029/JA087iA12p10519, 1982.

Moen, J., Oksavik, K., Alfonsi, L., Daabakk, Y., Romano, V., and Spogli, L.: Space weather challenges of the po- 
lar cap ionosphere, J. Space Weather Space Clim., 3, A02, doi:10.1051/swsc/2013025, 2013.

Mushini, S., Jayachandran, P., Langley, R., MacDougall, J., and Pokhotelov, D.: Improved amplitude and phase scintillation indices derived from wavelet detrended high-latitude GPS data, GPS Solut., 16, 363-373, doi:10.1007/s10291-011-0238-4, 2012.

Newell, P. T., Sotirelis, T., Liou, K., Meng, C.-I., and Rich, F. J.: A nearly universal solar wind-magnetosphere coupling function inferred from 10 magnetospheric state variables, J. Geophys. Res., 112, A01206, doi:10.1029/2006JA012015, 2007.

Prikryl, P., MacDougall, J. W., Grant, I. F., Steele, D. P., Sofko, G. J., and Greenwald, R. A.: Observations of polar patches generated by solar wind Alfvén wave coupling to the dayside magnetosphere, Ann. Geophys., 17, 463-489, doi:10.1007/s00585999-0463-0, 1999.

Prikryl, P., Jayachandran, P. T., Mushini, S. C., and Chadwick, R.: Climatology of GPS phase scintillation and HF radar backscatter for the high-latitude ionosphere under solar minimum conditions, Ann. Geophys., 29, 377-392, doi:10.5194/angeo-29-377-2011, 2011a.

Prikryl, P., Spogli, L., Jayachandran, P. T., Kinrade, J., Mitchell, C. N., Ning, B., Li, G., Cilliers, P. J., Terkildsen, M., Danskin, D. W., Spanswick, E., Donovan, E., Weatherwax, A. T., Bristow, W. A., Alfonsi, L., De Franceschi, G., Romano, V., Ngwira, C. M., and Opperman, B. D. L.: Interhemispheric comparison of GPS phase scintillation at high latitudes during the magnetic-cloudinduced geomagnetic storm of 5-7 April 2010, Ann. Geophys., 29, 2287-2304, doi:10.5194/angeo-29-2287-2011, 2011 b.

Prikryl, P., Jayachandran, P. T., Mushini, S. C., and Richardson, I. G.: Toward the probabilistic forecasting of highlatitude GPS phase scintillation, Space Weather, 10, S08005, doi:10.1029/2012SW000800, 2012.

Prikryl P., Sreeja, P. V., Aquino, M., and Jayachandran, P. T.: Probabilistic forecasting of ionospheric scintillation and GNSS receiver signal tracking performance at high latitudes, Ann. Geophys.-Italy, 56, R0222. doi:10.4401/ag-6219, $2013 \mathrm{a}$.

Prikryl, P., Ghoddousi-Fard, R., Kunduri, B. S. R., Thomas, E. G., Coster, A. J., Jayachandran, P. T., Spanswick, E., and Danskin, D. W.: GPS phase scintillation and proxy index at high latitudes during a moderate geomagnetic storm, Ann. Geophys., 31, 805816, doi:10.5194/angeo-31-805-2013, 2013b.

Prikryl, P., Jayachandran, P. T., Mushini, S. C., and Richardson, I. G.: High-Latitude GPS Phase Scintillation and Cycle Slips during High Speed Solar Wind Streams and Interplanetary Coronal Mass Ejections: A Superposed Epoch Analysis, Earth Planets Space, 66, 1-10, doi:10.1186/1880-5981-66-62, 2014.

Prikryl, P., Ghoddousi-Fard, R., Thomas, E. G., Ruohoniemi, J. M., Shepherd, S. G., Jayachandran, P. T., Danskin, D. W., Spanswick, E., Zhang, Y., Jiao, Y., and Morton, Y. T.: GPS phase scintillation at high latitudes during geomagnetic storms of 7-17 March 2012 - Part 1: The North American sector, Ann. Geophys., accepted, 2015a.

Prikryl ,P., Ghoddousi-Fard, R., Spogli, L., Mitchell, C. N., Li, G., Ning, B., Cilliers, P. J., Sreeja, V., Aquino, M., Terkildsen, M., Jayachandran, P. T., Jiao, Y., Morton,Y. T., Ruohoniemi, J. M., Thomas, E. G., Zhang, Y., Weatherwax, A. T., Alfonsi, L., De Franceschi, G., and Romano, V.: GPS phase scintillation at high latitudes during geomagnetic storms of 7-17 March 2012 -
Part 2: Interhemispheric comparison, Ann. Geophys., accepted, 2015b.

Prikryl, P., Ghoddousi-Fard, R., Ruohoniemi, J. M., and Thomas, E. G.: GPS phase scintillation at high latitudes during two geomagnetic storms, Auroral dynamics and space weather, edited by: Zhang, Y. and Paxton, L. J., AGU, Wiley Publ., accepted, 2015c.

Richardson, I. G. and Cane, H. V.: Near-Earth Interplanetary Coronal Mass Ejections During Solar Cycle 23 (1996-2009), Catalog and Summary of Properties, Sol. Phys., 264, 189-237, doi:10.1007/s11207-010-9568-6, 2010.

Rino, C. L. and Owen, J.: The Structure of Localized Nighttime Auroral Zone Scintillation Enhancements, J. Geophys. Res., 85, 2941-2948, doi:10.1029/JA085iA06p02941, 1980.

Secan, J. A., Bussey, R. M., Fremouw, E. J., and Basu, S.: An improved model of equatorial scintillation, Radio Sci., 30, 607-617, doi:10.1029/94RS03172, 1995.

Secan, J. A., Bussey, R. M., Fremouw, E. J., and Basu, S.: Highlatitude upgrade to the Wideband ionospheric scintillation model, Radio Sci., 32, 1567-1574, doi:10.1029/97RS00453, 1997.

Shepherd, S. G.: Altitude-adjusted corrected geomagnetic coordinates: Definition and functional approximations, J. Geophys. Res.-Space, 119, 7501-7521, doi:10.1002/2014JA020264, 2014.

Spogli, L., Alfonsi, L., De Franceschi, G., Romano, V., Aquino, M. H. O., and Dodson, A.: Climatology of GPS ionospheric scintillations over high and mid-latitude European regions, Ann. Geophys., 27, 3429-3437, doi:10.5194/angeo-27-3429-2009, 2009.

Spogli, L., Alfonsi, L., Cilliers, P. J., Correia, E., De Franceschi, G., Mitchell, C. N., Romano, V., Kinrade, J., and Cabrera, M. A.: GPS scintillations and total electron content climatology in the southern low, middle and high latitude regions, Ann. Geophys.Italy, 56, R0220, doi:10.4401/ag-6240, 2013.

Sreeja, V., Aquino, M., and Elmas, Z. G.: Impact of ionospheric scintillation on GNSS receiver tracking performance over Latin America: Introducing the concept of tracking jitter variance maps, Space Weather, 9, S10002, doi:10.1029/2011SW000707, 2011.

Strangeways, H. J., Ho, Y.-H., Aquino, M. H. O., Elmas, Z. G., Marques, H. A., Monico, J. F. G., and Silva, H. A.: On determining spectral parameters, tracking jitter, and GPS positioning improvement by scintillation mitigation, Radio Sci., 46, RS0D15, doi:10.1029/2010RS004575, 2011.

Tiwari, R. and Strangeways H. J.: Regionally based alarm index to mitigate ionospheric scintillation effects for GNSS receivers, Space Weather, 13, 72-85, doi:10.1002/2014SW001115, 2015.

Valladares, C. E., Carlson Jr., H. C., and Fukui, K.: Interplanetary magnetic field dependency of stable sun-aligned polar cap arcs, J. Geophys. Res., 99, 6247-6272, 1994.

Van Dierendonck, A. J. and Arbesser-Rastburg, B.: Measuring ionospheric scintillation in the equatorial region over Africa, including measurements from SBAS geostationary satellite signals, Proceeding of ION GNSS 17th technical meeting of the satellite division, Long Beach, CA, USA, 316-324, 2004.

Wernik, A. W., Liu, C. H., Franke, S. J., and Gola, M.: Highlatitude irregularity spectra deduced from scintillation measurements, Radio Sci., 25, 883-895, doi:10.1029/RS025i005p00883, 1990. 
Wernik, A. W., Alfonsi, L., and Materassi, M.: Scintillation modeling using in situ data, Radio Sci., 42, RS1002, doi:10.1029/2006RS003512, 2007.
Zhang, L., Morton, Y., Zhou, Q., van Graas, F., and Beach, T.: Characterization of GNSS signal parameters under ionosphere scintillation conditions using software-based tracking algorithms, Proc. IEEE PLANs Conf., Palm Springs, CA, USA, 2010. 